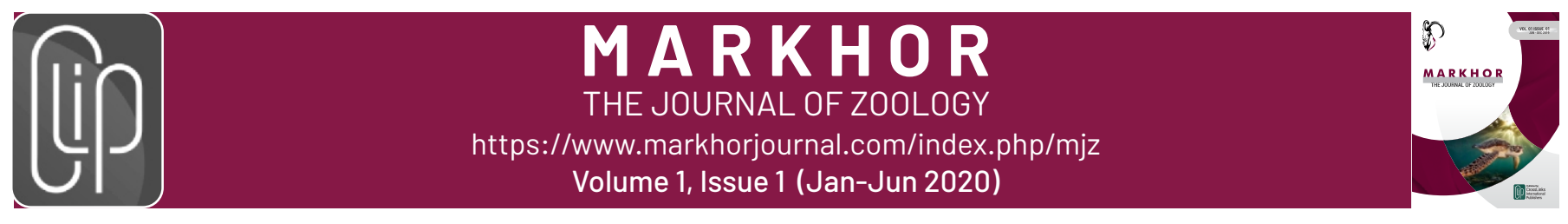

\title{
Review
}

\section{Biological Uses and Importance of Iron Regulation}

\section{Ammarah Hasnain ${ }^{* *}$ and Shazia Kanwal}

'Institute of Biochemistry and Biotechnology, The University of Lahore, Lahore, Pakistan

${ }^{2}$ Lahore College for Women University, Lahore, Pakistan

\section{A R T I C L E I N F O}

\section{Key Words:}

Iron metabolism, iron regulation, erythrocytes

\section{*Corresponding Author:}

Ammarah Hasnain

Ammarahnaqvi114@yahoo.com

\begin{abstract}
A B S T R A C T
Iron is an exceedingly important nutrient of the human body that has the ability to proceed the formation of free radicals and helps in the process of redox cycling with many different roles in metastasis and in microenvironment. It is required for many complex biological processes occurring in cells and inevitable for its viability and human survival. Such processes include oxygen transportation within body, cell proliferation and growth. It produces free radicals and has redox cycling capacity which may be responsible for tumorigenesis as well. Iron metabolic pathways are new therapeutic strategies for improving cancer prognosis and treatment as reprogramming of iron metabolism is a key aspect for tumor cells growth and survival
\end{abstract}

\section{N T R O D U C T I O N}

Iron is mostly present in the erythrocytes in the form of hemoglobin which is iron-containing oxygen-transport metalloprotein composed of four units, each containing one heme group and one protein chain [1] and is fundamental unit for overall uprightness \& health of digestive tract epithelia and its contribution to normal functions of enzymes [2] including signal transduction and cell regulation [3]. Iron has many fundamental functions in the body (Table 1). It acts as a fundamental part of vital enzymatic pathways in many tissues of the body, serves as a transport system for oxygen supply to the tissues from the lungs by iron carrying protein, haemoglobin and serves as a transport medium for electrons within cells $[4,5]$. The factors that may contribute to any alteration in metabolism of iron in cancer are signaling through hypoxia induced-factor (HIF) and WNT pathways [6]. Iron is an exceedingly important nutrient of the human body that has the ability to proceed the formation of free radicals and helps in the process of redox cycling with many different roles in metastasis and in microenvironment. It is required for many advanced and complicated pathways that continuously take place at a cellular and molecular level. They are also inevitable for sustainability of human life, e.g. the transportation of oxygen in all body cells.

\begin{tabular}{|l|l|}
\hline FUNCTION & PROTIEN \\
\hline Oxygen transport and storage & $\begin{array}{l}\text { Haemoglobin is a protein in RBCs that } \\
\text { transports oxygen in the blood and for } \\
\text { muscles, myoglobin protein serves } \\
\text { this purpose }\end{array}$ \\
\hline Oxygen homeostasis & $\begin{array}{l}\text { It is an iron-dependent prolyl- } \\
\text { hydroxylase enzyme that is crucial for } \\
\text { the physiological hypoxic response }\end{array}$ \\
\hline DNA synthesis & $\begin{array}{l}\text { Ribonucleotidereductase is required } \\
\text { for DNA synthesis }\end{array}$ \\
\hline plectron transport \& energy & $\begin{array}{l}\text { Cytochromes and dehydrogenases } \\
\text { are also important proteins and } \\
\text { components of the energy production } \\
\text { pathways in mitochondrion }\end{array}$ \\
\hline Metabolism \& detoxification & $\begin{array}{l}\text { Cytochromes are also involved in the } \\
\text { metabolism of biological molecules } \\
\text { and degradation and detosification of } \\
\text { drugs and pollutants }\end{array}$ \\
\hline Antioxidant activity & $\begin{array}{l}\text { Catalase and peroxidases are involved } \\
\text { in the metabolic regulation of } \\
\text { hydrogen peroxide in order to prevent } \\
\text { the cell from damage }\end{array}$ \\
\hline Beneficial & $\begin{array}{l}\text { Myeloperoxidase generates reactive } \\
\text { oxygen species inside neutrophils to } \\
\text { facilitate bacterial cell killing }\end{array}$ \\
\hline
\end{tabular}

Table 1: The biological uses of iron 
The lining cells of intestines can either preserve iron as ferritin, which is completed by $\mathrm{Fe}^{3+}$ binding to apoferritin or the cell can move it into the body, ferroportin which is encoded by SLC40A1 gene and is also also known as solute carrier family 40 member 1 (SLC40A1)

[7]. The absorbed iron from the intestines is converted into 'ferritin' and resides there or is transported via plasma as 'transferrin'. The precursors of erythrocytes get iron for the production of hemoglobin from this transferrin in plasma or from the recycling of older erythrocytes that are mature or about to degrade by immune cells in bone marrow, spleen and liver. Iron levels in body are regulated and maintained by these phases. As an example, cells synthesize more Dcytb, DMT1 and ferroportin as a result of iron deficiency anemia. When iron is stored as ferritin, it leaves the body as feaces after the cell dies. Absorption of iron from digested food is increased with Vitamin $C$ and decreases if there is excess of calcium, zinc and magnesium is present [8]. The excess iron after hemoglobin synthesis is preserved in immune cells as ferritin which is then oxidized to hemosiderin. These reserves can be used during the times of need $[9,10]$.

\section{Importance of Iron Regulation:}

Iron is a basic and important component of a living cell but but there is no physiological mechanism to get rid of excess of it. It is required for transportation of oxygen and survival of all cancerous cells [11-13]. It has the capability of donation and acceptance of electrons, meaning that it is freely available in cell and can transform hydrogen peroxide into free radicals. These free radicals have many important roles that are crucial for life e.g. detoxification, killing harmful agents such as bacterial and viruses by phagocytosis. Free radicals are also used in cell signaling processes. On the other hand, excessive amounts of free radicals are the main cause of damage and killing to the vast variety of cellular structures that may lead to many diseases such as diabetes, cancer, stroke, myocardial infarction etc. All kind of living cells that use iron binds these atoms to proteins to eradicate this type of damage. It allows them to use the advantages of iron, but at the same time, it also restricts its capacity to do harm do harm[14-18].

\section{Loss of Iron:}

A study conducted by Green, it is found that the total amount of iron which is lost is $14 \mu \mathrm{g} / \mathrm{kg}$ body weight/day approximately. Iron is only lost with the cells of interior surfaces of the body and with the cells from the skin and it is not disposed of from the body via e urine or in the intestines [19]. Some new studies suggested that during the collection of total body sweat, some precautionary measures should be followed to prevent the chances of contamination of iron from the skin. The results show that there is a negligible loss of iron in the sweat. In contrary to new studies, someprevious researchers found that sweat iron losses could be sufficient in the hot temperate climate [20,21]. Iron losses also occurs during prolonged exercises [22]. People loss a small but firmly amount by sweating \& by mucosal lining of the gastrointestinal tract and by shedding cells off the skin. However, the body iron is recycled by the reticuloendothelial system. In the developed world, the total amount of loss for normal and healthy humans estimates 1 $\mathrm{mg}$ per day for males, and 1.5-2 mg a day for females with regular menstrual periods $1 \mathrm{mg}$ a day and $1.5-2 \mathrm{mg}$ a day for men and females with regular menstruation cycles. This gradual loss shows that people should consume and absorb iron regularly to have normal physiological functionally as well as to prevent iron overloading which may cause certain pathologies including cancers[15].

\section{R E F E R E N C E S}

[1] Severinghaus, J. W. Oxyhemoglobin dissociation curve correction for temperature and $\mathrm{pH}$ variation in human blood. J Appl Physiol, 1958, 12(3): 485-486.

[2] Rajendran, R., T. Vijayakumar, et al. An alternative pathogenetic pathway for oral submucous fibrosis (OSMF). Med Hypotheses, 1989, 30(1): 35-37.

[3] Hunter, T. "Protein kinases and phosphatases: the yin and yang of protein phosphorylation and signaling. Cell, 1995, 80(2): 225-236

[4] Mascotti, D. P., D. Rup, et al. Regulation of iron metabolism: translational effects mediated by iron, heme, and cytokines. Annu Rev Nutr, 1995, 15: 239261.

[5] von Drygalski, A. and J. W. Adamson. Iron Metabolism in Man. JPEN J Parenter Enteral Nutr., 2012.

[6] Torti, S. V. and F. M. Torti. Iron and cancer: more ore to be mined. Nat Rev Cancer, 2013, 13(5): 342-355.

[7] Donovan, A., A. Brownlie, et al. Positional cloning of zebrafish ferroportin1 identifies a conserved vertebrate iron exporter. Nature, 2000, 403(6771): 776-781.

[8] Fleming, R. E. and B. R. Bacon. Orchestration of iron homeostasis. NEngl J Med, 2005, 352(17): 1741-1744.

[9] Frazer, D. M. and G. J. Anderson. Iron imports. I. Intestinal iron absorption and its regulation. Am J Physiol Gastrointest Liver Physiol, 2005, 289(4): 
G631-635.

[10] Fleming, R. E. and R. S. Britton (2006). "Iron Imports. VI. HFE and regulation of intestinal iron absorption." Am J Physiol Gastrointest Liver Physiol 290(4): G590594.

[11] Blanc, J. F., P. Bioulac-Sage, et al. (2000). "[Iron overload and cancer]." Bull Acad Natl Med 184(2): 355-363.

[12] D'Souza, G., A. R. Kreimer, et al. Case-control study of human papillomavirus and oropharyngeal cancer. $\mathrm{N}$ Engl J Med, 2007, 356(19): 1944-1956.

[13] Jian, J., Q. Yang, et al. Effects of iron deficiency and iron overload on angiogenesis and oxidative stress-a potential dual role for iron in breast cancer. Free Radic Biol Med, 2011, 50(7): 841-847.

[14] Andrews, N. C. Disorders of iron metabolism. N Engl J Med, 1999, 341(26): 1986-1995.

[15] Conrad, M. E. and J. N. Umbreit (2000). "Disorders of iron metabolism." N Engl J Med 342(17): 1293-1294.

[16] Pacher, P., J. S. Beckman, et al. (2007). Nitric oxide and peroxynitrite in health and disease. Physiol Rev, 2007, 87(1): 315-424.

[17] 3373-3378.

[18] Manivasagam, T., P. Anantharaman, et al. Chemopreventive effect of Padina boergesenii extracts on ferric nitrilotriacetate (Fe-NTA)-induced oxidative damage in Wistar rats. J. Appl. Phycol., 2011, 23(2): 257(252): 257-263.

[19] Green, R., R. Charlton, et al. Body iron excretion in man: a collaborative study. Am J Med, 1968, 45(3): 336-353.

[20] Vellar, O. D. Studies on sweat losses of nutrients. II. The influence of an oral iron load on the iron content of whole body cell-free sweat. Scand $J$ Clin Lab Invest, 1968, 21(4): 344-346.

[21] Brune, M., B. Magnusson, et al. Iron losses in sweat. Am J Clin Nutr, 1986, 43(3): 438-443.

[22] DeRuisseau, K. C., S. N. Cheuvront, et al. Sweat iron and zinc losses during prolonged exercise. Int J Sport NutrExerc Metab, 2000, 12(4): 428-437. 